\title{
Indicadores Econômicos da Região Metropolitana da Grande São Luís
}

\section{Economic Indicators of the Metropolitan Region of the Great São Luís}

\author{
Yata Anderson Gonzaga Masullo * \\ José Antonio Viana Lopes**
}

\section{Resumo:}

A partir do ano de 2015, a Região Metropolitana da Grande São Luís - RMGSL foi reestruturada, com a inclusão dos municípios de Axixá, Cachoeira Grande, Morros e Presidente Juscelino, entre outras ações. Esses municípios sofrem os impactos da forte interação e concentração econômica, social e urbana, sem contar com um sistema consistente de planejamento e gestão metropolitana compartilhada que minimize os riscos desta interação e apresente soluções para os problemas vividos pela população. Este estudo tem o objetivo de analisar e caracterizar a nova configuração da RMGSL, a partir de indicadores econômicos e sociais (Dinâmica Populacional; Taxa de Urbanização; Produto Interno Produto - PIB, Renda e População na Força de Trabalho) refletindo sobre o desenvolvimento e a situação da mesma, com o intuito de compreender a realidade metropolitana em sua totalidade, para além das simples análises operacionais e setoriais. Parte-se da hipótese de que mesmo em uma região metropolitana com atores em diferentes estágios de desenvolvimento e com predominância do setor primário e urbanização incompleta, pode-se visualizar potenciais socioambientais e econômicos, que com ações conjuntas e compartilhadas sejam capazes de dinamizar e reestruturar o desenvolvimento socioespacial.

\section{Abstract:}

From the year 2015, the metropolitan area of Greater São Luís - RMGSL was restructured to include the municipalities of Axixá, Cachoeira Grande, Morros and Presidente Juscelino, among other actions. These municipalities are suffering the impacts of the strong interaction and economic concentration, social and urban, not counting a consistent system planning and shared metropolitan management that minimizes the risks of this interaction and present solutions to the problems experienced by the population. This study aims to analyze and characterize the new configuration of RMGSL, from economic and social indicators (Population Dynamics; urbanization rate; domestic product Product - GDP, income and population in the Workforce) reflecting on the development and the same situation, in order to understand the metropolitan reality in its entirety, beyond simple operational and sector analysis. It starts with the hypothesis that even in a metropolitan area with actors at different stages of development and predominance of the primary sector and incomplete urbanization, you can view environmental and economic potential, which with joint efforts and shared will be able to streamline and restructure the social and spatial development.
* Mestre em Desenvolvimento Socioespacial e Regional pela UEMA. Pesquisador do Instituto Maranhense de Estudos Socioeconômicos e Cartográficos -IMESC, Consultor da empresa Ambiental Gestão de Projetos e Professor Assistente de Cartografia e Geoprocessamento da Faculdade CEST.

** Metre em Planejamento Urbano pela UFPE. Secretário Adjunto de Assuntos Metropolitanos do Estado do Maranhão

\section{Palavras-chave:}

Dinâmica Espacial, Indicadores Econômicos, Região Metropolitana da Grande São Luís

Key-Words:

Space Dynamics, Economic indicators, Metropolitan region of Greater São Luís 


\section{INTRODUÇÃO}

$\mathrm{O}_{\mathrm{s}}^{\mathrm{p}}$ processo histórico de formação das cidades e regiões metropolitanas brasileiras foi descontínuo, mas centrado nos ciclos econômicos do país. Deste modo, compreender o processo de instituição, consolidação e funcionamento das regiões metropolitanas, em particular no Brasil de hoje, é compreender um pouco mais do funcionamento e da dinâmica do capitalismo contemporâneo, notadamente a partir da forma como nele se produz o espaço social urbano (IPEA, 2010).

O que se tornou uma questão central nos últimos estudos sobre as Regiões Metropolitanas foi a forma de tratamento e análise das ações dos agentes envolvidos no planejamento e gestão das regiões, por estes pensarem o local de forma segregada e isolada e não ampliando e flexibilizando os interesses entre os municípios que constituem tal região. Tal problemática se torna ainda mais abrangente quando se contabiliza no Brasil, 71 Regiões Metropolitanas (RMs), 4 Aglomerações Urbanas (AUs) e 3 Regiões Integradas de Desenvolvimento (RIDEs) (OBSERVATÓRIO DA METRÓPOLE, 2015).

Dentre elas está a Região Metropolitana da Grande São Luís - RMGSL. Atualmente a mesma conta com uma população de 1.590 .138 habitantes, concentrando $42 \%$ do PIB do Estado do Maranhão (IPEA, 2013; IBGE, 2015). Contudo, ainda apresenta problemas estruturais, como a desigualdade de renda, com aproximadamente $5 \%$ da população vivendo abaixo da linha da extrema pobreza, alto déficit habitacional, com cerca de $20 \%$ da população residindo em aglomerados subnormais (IBGE, 2010); aumento dos índices de violência da ordem de 24,7\% em 2014, problemas de mobilidade intermunicipais, com uma frota que supera os 370 mil veículos e a indefinição dos limites municipais; além de problemas e lacunas na sua lei de criação e no processo de institucionalização e efetivação.

Assim o trabalho aqui desenvolvido tem por objetivo caracterizar social, ambiental e economicamente a Região Metropolitana da Grande São Luís - MA, a partir das transformações territoriais decorrentes do planejamento urbano e da proposta de efetivação da gestão metropolitana compartilhada, à luz do Estatuto da Metrópole (Lei 13.089 de janeiro de 2015) para a promoção do desenvolvimento regional metropolitano.

\section{MATERIAIS E MÉTODOS}

Para o presente trabalho, idealizou-se um modelo para a elaboração do estudo, utilizando o método hipotético-dedutivo proposto por Popper (1975), onde parte-se de hipóteses formuladas para deduzir implicações e consequências da relação homem-natureza, sobre os setores da sociedade com destaque para as questões socioeconômicas.

Em linhas gerais, o trabalho evidencia a integração de uma série de dados específicos de forma multidisciplinar, tratando da correlação dos elementos envolvidos. A pesquisa documental será tanto através da consulta na Secretaria de Estado das Cidades e Desenvolvimento Urbano - SECID, Secretaria de Adjunta de Assuntos Metropolitanos - SAAM, Universidade Federal do Maranhão e Universidade Estadual do Maranhão. Para a análise bibliográfica, foi sistematizada pesquisa acerca das publicações existentes sobre o tema (livros, artigos, monografias, teses, trabalhos técnicos, etc.).

Relativo às questões socioeconômicas e cartográficas foram selecionados indicadores em nível municipal obtidos no Instituto Brasileiro de Geografia e Estatística - IBGE e Instituto Maranhense de Estudos Socioeconômicos e Cartográficos - IMESC. Em escala municipal serão coletados dados referentes aos indicadores econômicos (Dinâmica Populacional; Taxa de Urbanização; Produto Interno Produto - PIB, Renda e População na Força de Trabalho). Os dados citados foram espacializados na base cartográfica da RMGSL com o emprego do Software Arc Giz 10.2 e técnicas do Sistema de Informação Geográfico - SIG.

\section{HISTÓRICO DA GRANDE SÃO LUÍS}

Entre as décadas de 1980 e 1990, houve um rápido processo de urbanização da capital do Maranhão, devido a fatores que atraíram um grande contingente populacional para o município de São Luís como, a política territorial vinculada ao Programa Grande Carajás. Esta foi desenvolvida a partir da instalação da Vale do Rio Doce e ALUMAR, com investimentos da ordem de $\mathrm{R} \$ 224$ milhões, que transformaram a região em pólo de atração de mão de obra, atraindo inúmeras empreiteiras, o que agravou os problemas urbanos.

A região passou por um intenso processo de periferização nesse período, os recortes espaciais seguiam a lógica da ocupação de terras públicas ou glebas não ocupadas, dando origem ao processo de ocupação desordenada em São Luís.

Esses projetos com um discurso desenvolvimentista provocaram também um deslocamento de um grande contingente populacional do interior do estado, de estados vizinhos e outras regiões para a capital maranhense induzindo, desse modo, uma ampliação do setor de serviços. Os Complexos Industriais que se instalam no Maranhão, apesar do seu grande investimento, não disponibilizam na mesma medida o número de empregos 
diretos no estado e na sua capital São Luís (MOREIRA, 2013, p. 40).

No desenrolar desse processo, algumas questões de como gerir uma cidade que cresce a um ritmo acelerado e de encontro com outros municípios da ilha foram colocados em discussão, entretanto, as medidas adotadas fracassaram do ponto de vista prático. Isto é, no final da década de 1990, foi elaborado o projeto de lei de criação da Região Metropolitana da Grande São Luís - RMGSL, aprovada em 1998, através da Lei Complementar Estadual no 038/98, englobando todos os municípios da Ilha do Maranhão (São Luís, São José de Ribamar, Paço do Lumiar e Raposa), de autoria do Deputado Francisco Martins.

Posteriormente foi aprovada a Lei Complementar Estadual no 69/03 de autoria do Deputado Alberto Franco, que dava nova estrutura à RMGSL acrescentando o município de Alcântara, além de reestruturar a formação do Conselho de Administração e Desenvolvimento da Região Metropolitana da Grande São Luís - COADEGS.

Já em 2013 houve nova alteração na configuração da RMGSL a partir da formulação da Lei Complementar Estadual no 153, de 10 de abril de 2013 de autoria do Deputado Jota Pinto que incorporou os municípios de Bacabeira, Rosário e Santa Rita e logo em seguida, houve mais uma alteração pela Lei Complementar Estadual no 161, de 03 de dezembro de 2013 de autoria do Deputado Eduardo Braide que incorporou o Município de Icatu.

Recentemente em 2015 houve uma nova alteração da configuração e estrutura da RMGSL com o objetivo de implementar os instrumentos de gestão metropolitana e as especificações determinadas pela Lei Federal no 13.089, de 12 de janeiro de 2015 que institui o Estatuto da Metrópole. Assim por iniciativa do Poder Executivo liderado pela Secretaria de Estado das Cidades e Desenvolvimento Urbano - SECID e participação efetiva dos municípios integrados a RMGSL foi discutida e aprovada a Lei Complementar Estadual $n^{\circ}$ 174 de maio de 2015, que dispõe sobre a instituição e gestão do Colegiado e Conselho Metropolitano, criação da Agência Executiva, Fundo e Sistema de Informação Metropolitano, além de incluir na composição da RMGSL os municípios de Axixá, Cachoeira Grande, Morros e Presidente Juscelino.

\section{NOVA CONFIGURAÇÃO METROPOLITA- NA DA GRANDE SÃO LUÍS}

Com a entrada em vigor da Lei Federal $\mathrm{n}^{\circ}$ 13.089/2015, houve um inevitável incômodo acerca dos ajustes e adequação das Regiões Metropolitanas, pois somente seriam reconhecidas as Regiões Metropolitanas que efetivassem seus planos de gestão, de acordo com o seu artigo $8^{\circ}$, que trata sobre a estrutura de governança interfederativa:

Art. $8^{\circ}$ A governança interfederativa das regiões metropolitanas e das aglomerações urbanas compreenderá em sua estrutura básica:

I - instância executiva composta pelos representantes do Poder Executivo dos entes federativos integrantes das unidades territoriais urbanas;

II - instância colegiada deliberativa com representação da sociedade civil;

III - organização pública com funções técnico-consultivas; e IV - sistema integrado de alocação de recursos e de prestação de contas. (BRASIL, 2015).

Nesse contexto, temos ao mesmo tempo a inauguração de uma nova forma de gestão do território, agora regulamentada, e do outro, os velhos dilemas institucionais de gestão metropolitana como a fragmentação política, que desde a criação da RMGSL travou a efetividade do processo de metropolização.

Criada em 2011 e vinculada à Casa Civil do Estado até o ano de 2014, a Secretaria Adjunta de Assuntos Metropolitanos - SAAM não obteve sucesso na articulação entre os municípios componentes da RM. Em 2015, com a mudança de vínculo institucional para a Secretaria de Estado das Cidades e Desenvolvimento Urbano - SECID e uma nova visão estratégica do atual governo do Estado, uma nova reestruturação da RMGSL foi consolidada através de reuniões regulares entre representantes do Governo Estadual, Municipal e Sociedade Civil.

A nova configuração da RMGSL lançada incorporou municípios com dois objetivos claros: consolidar a configuração atual, integrando todos os municípios da região do Baixo Munim (Axixá, Cachoeira Grande, Morros e Presidente Juscelino) ainda não inclusos, e viabilizar o processo de desenvolvimento dos mesmos com foco em projetos específicos nas áreas e serviços de interesse comum entre os entes municipais, reduzindo as desigualdades intrametropolitanas.

Atualmente, São Luís e os municípios de Alcântara, Axixá, Bacabeira, Cachoeira Grande, Icatu, Morros, Paço do Lumiar, Presidente Juscelino, Raposa, São José de Ribamar, Rosário e Santa Rita que compõem a região metropolitana (Figura 01). Estes municípios sofrem os impactos da forte interação e concentração econômica, social e urbana, sem contar com um sistema consistente de planejamento e gestão metropolitana compartilhada que minimize os riscos desta interação e apresente soluções para os problemas vividos pela população.

O mapa acima indica a nova configuração da RMGSL, que será viabilizada e efetivada para além de conceitos estruturais pré-definidos com um volume de projetos e investimentos específicos para a região, haja vista a extrema necessidade de estruturação de municípios como Presidente 
Juscelino, Cachoeira Grande, Morros, Axixá e Icatu que ainda se encontram em um processo de urbanização incompleto e com serviços públicos deficientes, revelando uma descontinuidade espacial e urbana dentro da RMGSL. que se encontram sob sua área de influência (Figura 02).

O desafio que se faz presente na configuração e efetivação de metrópoles, principalmente as brasileiras, é o de planejar de modo não-racionalista e flexível.

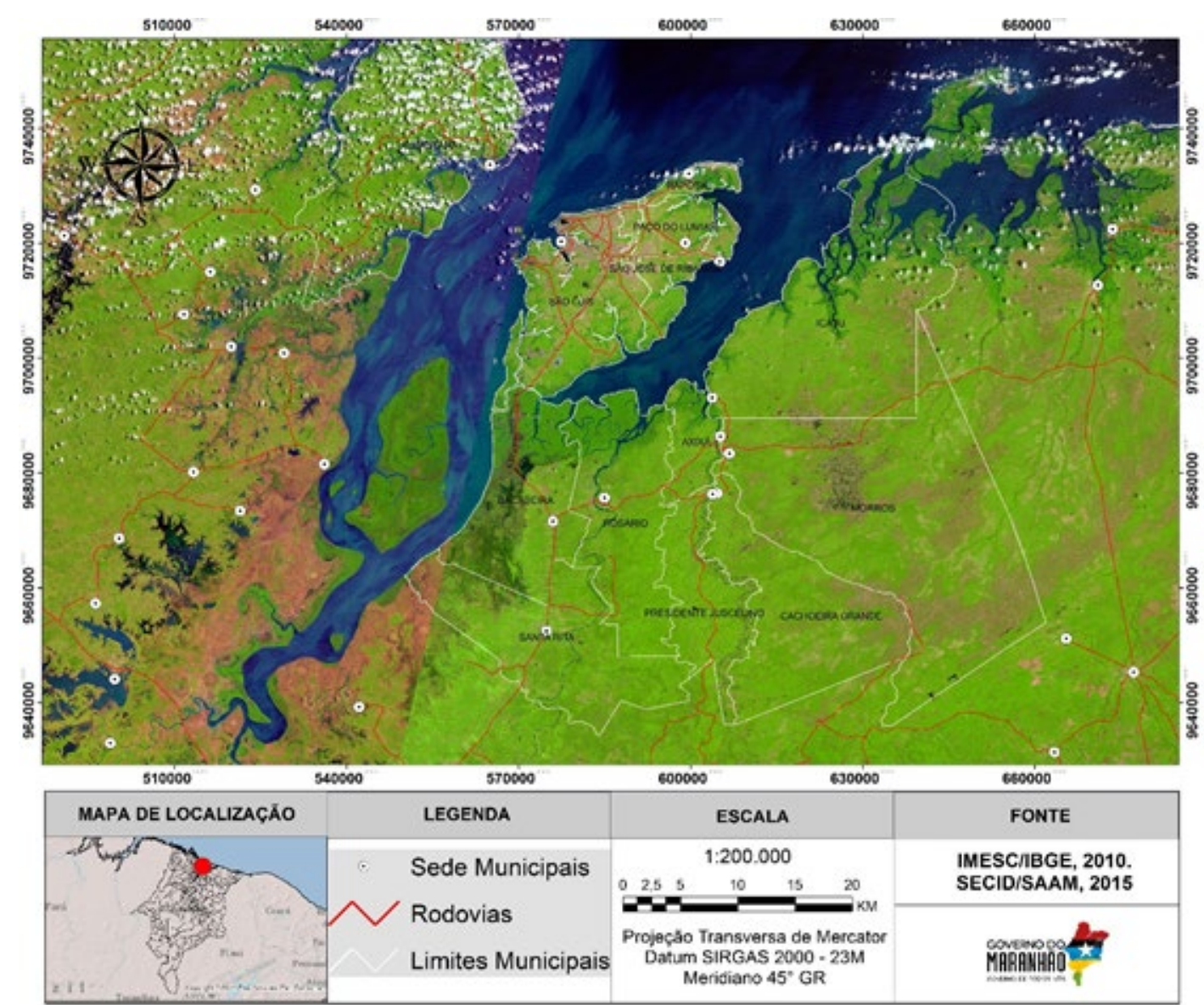

Figura 01: Imagem de satélite da Região Metropolitana da Grande São Luís Fonte: SECID/SAAM, 2015

Portanto, o governo do estado, juntamente com os entes municipais se propõe a efetivar a Grande São Luís a partir de instrumentos de planejamento e gestão que integrem e consolidem a Região Metropolitana, com mecanismos e infraestrutura voltada para essa nova configuração, objetivando o desenvolvimento de planos, projetos e acesso a incentivos fiscais ligadas aos sistemas de comunicação, saúde, habitação, transporte, dentre outros.

Sob tal perspectiva o interesse comum de serviços urbanos é condição sine qua non para configuração de uma Região Metropolitana interligada as entidades municipais e a sociedade civil. Com o foco para a RMGSL, tem-se na atual configuração uma ligação intrínseca entre os municípios da Ilha do Maranhão e uma polarização de municípios vizinhos
Nesta perspectiva, entende-se que a história é uma mistura complexa de determinação e indeterminação, de regras e de contingência, de condicionamento estrutural e de graus de liberdade para a ação individual, em que o esperável é frequentemente sabotado pelo inesperado - o que torna qualquer planejamento algo, ao mesmo tempo, necessário e arriscado (SOUZA, 2010).

Investiga-se, portanto, se em uma região metropolitana predominância do setor primário e urbanização incompleta - situação consolidada com a inclusão de novos municípios - pode-se visualizar potenciais socioambientais e econômicos, que com ações conjuntas e compartilhadas sejam capazes de dinamizar e reestruturar o desenvolvimento socioespacial. 


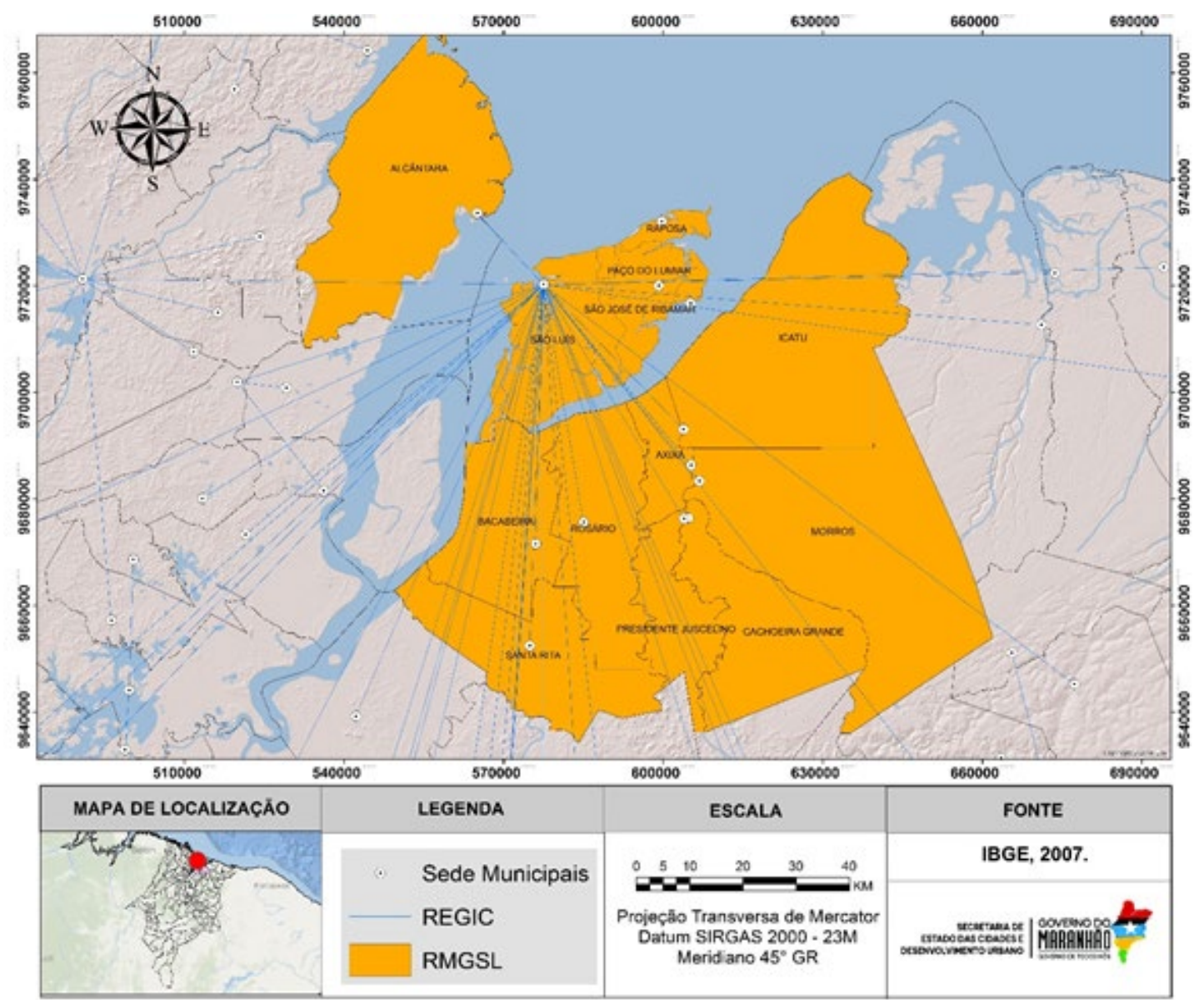

Figura 02: Mapa da Região de Influência da RMGSL Fonte: SECID/SAAM, 2015.

Fonte: SECID/SAAM, a partir de dados de IBGE, 2007.

\section{CARACTERIZAÇÃO ECONÔMICA DA GRANDE SÃO LUÍS}

Os aspectos socioeconômicos das Regiões Metropolitanas devem ser analisados de forma qualitativa, pois através deles se pode perceber os níveis de qualidade de vida da população, com acesso a serviços essenciais à vida urbana. Portanto, a questão metropolitana não pode ser pensada de maneira unilateral, levando em consideração o poder de articulação e a questão regional.

Referente à RMGSL, tem-se um volume concentrado de infraestrutura na cidade pólo, esse fator gera duas situações que afetam diretamente uma gama de pessoas que precisam dessa infraestrutura. O primeiro fator é a aglomeração de pessoas que se dirigem à capital em busca de serviços públicos ou atendimento privado, um exemplo disso é o atendimento clínico hospitalar: esse serviço é ofertado precariamente por vários municípios vizinhos e longínquos de São Luís o que converge na disputa por um atendimento na rede hospitalar da cidade com o aumento geométrico na demanda local.
Outro fator é a ausência de uma infraestrutura básica nesses municípios, provocando um decréscimo da qualidade de vida da população que dificulta a atração de investimentos privados para esses municípios, alicerçado pelas décadas de ineficácia dos investimentos públicos. Apesar desta concentração na cidade pólo, em termos regionais persiste o fato de que o município de São Luís ainda apresenta baixa oferta de serviços, em comparação com Regiōes Metropolitanas da Região Nordeste.

Assim, uma análise dos índices sociais, políticos e econômicos é um começo para mensurar as barreiras e empecilhos que a efetivação da metropolização impõe às políticas urbanas e a gestão intergovernamental de uma RM.

\subsection{Dinâmica Populacional}

A demanda populacional crescente na área urbana torna-se um problema para o poder público a partir do momento em que a cidade não suporta acolher um contingente elevado que passa a ocupar áreas desprovidas de qualquer 
estrutura urbana. Nesse sentido, passa a ser percebida nas novas áreas de ocupação da cidade assumem um caráter de áreas periféricas, resultando em uma a equação onde o que é sustentável e suportável resulta em perda da qualidade de vida urbana (Figura 03; Tabela 01).

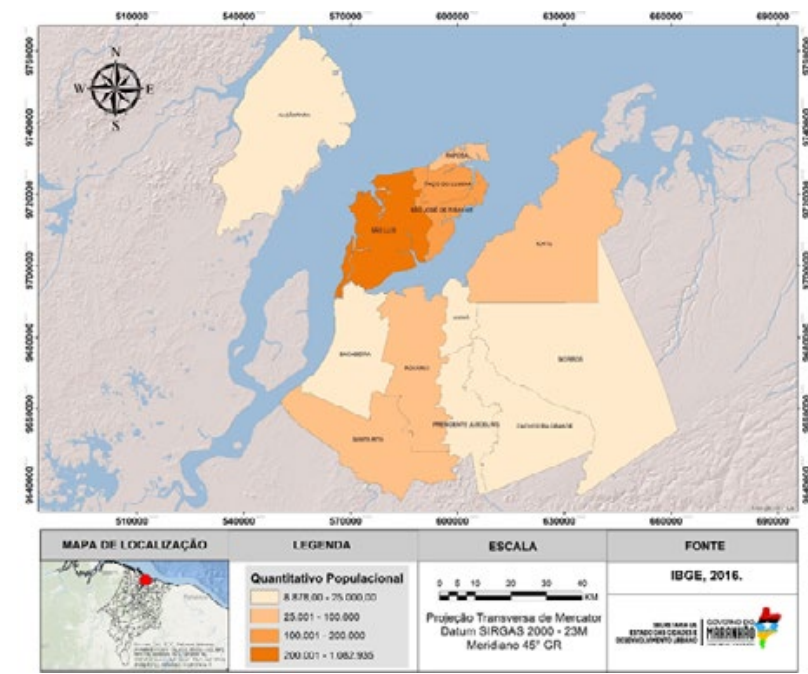

Figura 03: Mapa do Quantitativo Populacional da RMGSL em 2010. Fonte: IBGE, 2015.

Tabela 01: Evolução populacional dos municípios RMGSL entre 2000 a 2016.

\begin{tabular}{|cccccc|}
\hline MUNICíPIO & $\mathbf{2 0 0 0}$ & $\begin{array}{c}\text { Tx de } \\
\text { Crescimento }\end{array}$ & $\mathbf{2 0 1 0}$ & $\begin{array}{c}\text { Tx de } \\
\text { Crescimento }\end{array}$ & $\mathbf{2 0 1 6}$ \\
\hline Aleântara & 21.291 & $3 \%$ & 21.851 & $-0.84 \%$ & 21.667 \\
\hline Axixá & 10.142 & $12 \%$ & 11.407 & $4,30 \%$ & 11.915 \\
\hline Bacabeira & 10.516 & $42 \%$ & 14.925 & $11,30 \%$ & 16.812 \\
\hline Cachoeíra Grande & 7.383 & $14 \%$ & 8.446 & $4,90 \%$ & 8.878 \\
\hline Icatu & 21.489 & $17 \%$ & 25.145 & $5,70 \%$ & 26.651 \\
\hline Morros & 14.594 & $23 \%$ & 17.883 & $6,50 \%$ & 19.116 \\
\hline Paço do Lumiar & 76.188 & $38 \%$ & 104.881 & $12,60 \%$ & 119.915 \\
\hline Presidente Juscelino & 10.693 & $8 \%$ & 11.541 & $7,90 \%$ & 12.532 \\
\hline Raposa & 17.088 & $54 \%$ & 26.327 & $13.20 \%$ & 30.304 \\
\hline Rosário & 33.665 & $18 \%$ & 39.576 & $5,10 \%$ & 42.016 \\
\hline Santa Rita & 24.922 & $30 \%$ & 32.366 & $11,50 \%$ & 36.556 \\
\hline Såo José de Ribamar & 107.384 & $52 \%$ & 163.045 & $7,40 \%$ & 176.008 \\
\hline São Luís & 870.028 & $17 \%$ & 1.014 .837 & $6,30 \%$ & 1.082 .935 \\
\hline RMGSL & 1.225 .383 & $22 \%$ & 1.492 .230 & $7 \%$ & 1.605 .305 \\
\hline
\end{tabular}

Fonte: SECID/SAAM adaptado de IBGE, 2016.

De acordo com o IBGE (2015), a RMGSL conta atualmente com uma população de 1.605.305 habitantes. Aproximadamente $67 \%$ do quantitativo populacional está concentrado na Capital Maranhense, enquanto os municípios de Alcântara, Axixá, Bacabeira, Cachoeira Grande, Icatu, Morros, Raposa, Rosário e Presidente Juscelino contabilizam apenas $14,1 \%$ do quantitativo populacional da região.

Os municípios da RMGSL passaram por fortes transformações nos últimos anos com atração de novas empresas e investimentos, o que propiciou um considerável crescimento populacional entre 2000 a 2016. Raposa, São José de Ribamar, Paço do Lumiar e Bacabeira foram os municípios com crescimento mais expressivo, principalmente impulsio- nado pela instalação ou previsão de grandes projetos, já em Alcântara houve redução de habitantes entre os anos de 2010 a 2016, algo que pode ter sido gerado a partir da desmobilização das obras de ampliação do Centro de Lançamento de Alcântara.

Ressalta-se que entre 2014 e 2015 houve uma ampliação de $1,83 \%$ da população residente na RMGSL, deste, o maior crescimento populacional da região foi centralizado nos municípios de São José de Ribamar e São Luís com 11.342 e 9.696 habitantes respectivamente. Já entre 2015 e 2016 registra-se aumento de $0,94 \%$ no quantitativo populacional da RM, nesse processo identifica-se uma situação na qual a região sofre com os impactos gerados pela implantação de serviços e empreendimentos que afetam a todos, sem contar com políticas integradas para a solução destes problemas. É o caso, por exemplo, dos empreendimentos do Programa Minha Casa Minha Vida, em São José de Ribamar e na zona rural de São Luís que, por um lado, é resultado do processo de valorização da terra na capital que descentraliza a habitação popular, e por outro acentua as carências de serviços e infraestrutura, demonstrando a necessidade de implementação de mecanismos de integração a dinâmica metropolitana e ao gerenciamento do processo de urbanização.

\subsection{Taxa de Urbanização}

O avanço da urbanização intensifica mudanças no ambiente, influenciada pela dinâmica da cidade, que reflete o processo de produção e reprodução do espaço a partir de uma lógica de distribuição e consumo (LIPIETZ, 1979;

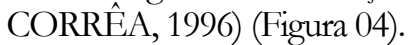

O percentual de urbanização demonstra e identifica a parcela da população que reside nas áreas urbanas e aquela que habita a zona rural. A RMGSL possui uma taxa de urbanização, segundo o IBGE (2010), de 63,37\%, com centralização de área conurbada nos municípios da Ilha do Maranhão com São Luís, Paço do Lumiar e Raposa alcançando respectivamente $94,45 \%$, 74,9\% e 63,33\%. Contudo, 40\% dos municípios da RMGSL possuem predominância de área rural e baixo percentual de urbanização como Alcântara, Bacabeira, Cachoeira Grande, Icatu, Morros e Presidente Juscelino.

\subsection{Infraestrutura Viária}

O crescimento dos centros urbanos funcionalmente articulados influencia em diversas escalas a organização territorial, o que reflete a integração dos sistemas produtivos, financeiro e sociocultural. Esse cenário demonstra a necessidade de reorientação das políticas que estruturam os eixos de centralidades existentes na região aproveitando o grau de interligação viário e marítimo, bem como a proximidade entre as sedes municipais que deve ser visto como importante condicionante para otimização da gestão em escala regional 
(Figura 05).

A região metropolitana está interligada ao interior do estado por meio de uma linha férrea e também aos estados vizinhos do Pará, Tocantins e Piauí o que facilita o escoamento agrícola e mineral. Por rodovia, é conectada pela BR135, MA 201; MA 202; MA 203; MA 204; MA 402 e MA 020; já por ar, conta com o Aeroporto Internacional Marechal Cunha Machado, além de possuir diversos portos que servem tanto para o escoamento da produção quanto para transporte de passageiros como o Porto do Itaqui e o Terminal Portuário da Praia Grande (Tabela 02).

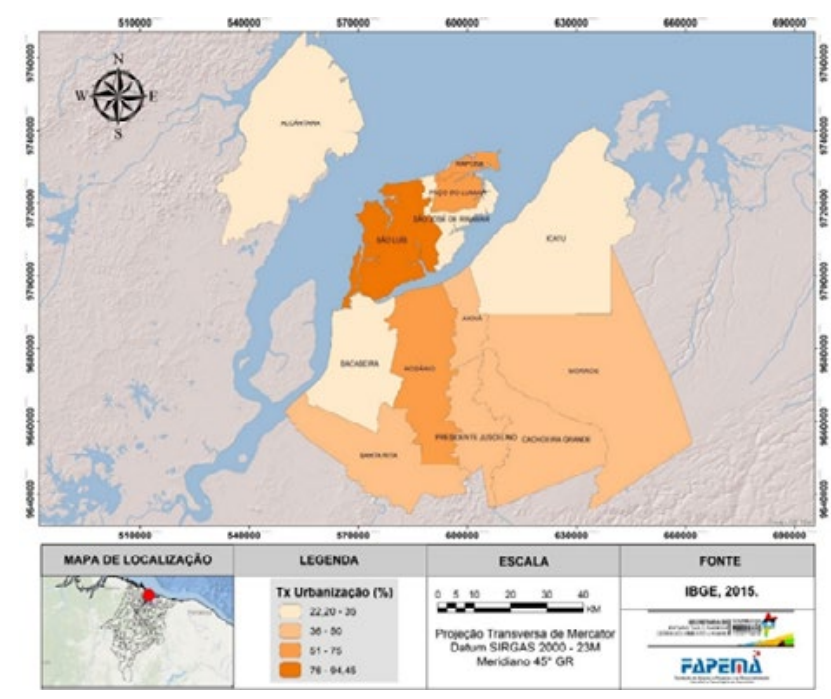

Figura 04: Mapa da Taxa de Urbanização da RMGSL em 2010. Fonte: IBGE, 2010.

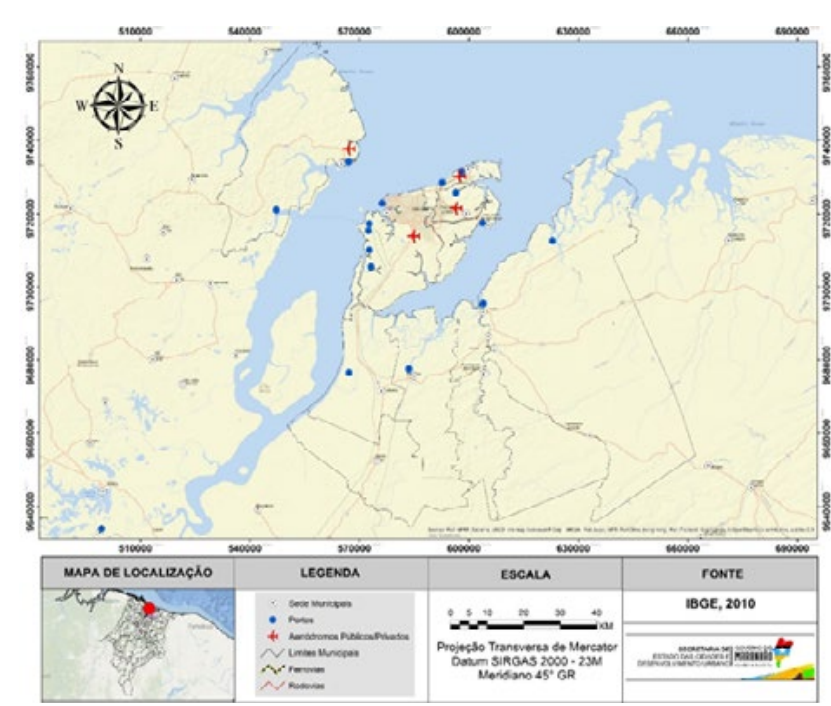

Figura 05: Mapa da estrutura Aeroviária, Ferroviária, Hidroviária e Rodoviária da RMGSL.

Fonte: MACROZEE, 2013; IBGE; 2015.

A localização condiciona o acesso e as barreiras, re- presentadas pela acessibilidade e poder de mobilidade que impacta em diferentes níveis e escalas a sociedade, com a geração de grandes demandas por mecanismos mais especializados oriundos do baixo grau de cobertura das redes (OLIVEIRA, 2008). Infere-se a esse sistema de (re) produção e consumo do espaço, o controle dos tempos de deslocamento e pela qualidade dos serviços, que são elementos fundamentais e parte integrante das práticas espaciais dos agentes sociais.

Tabela 02: Distâncias através das vias acesso entre a Capital Maranhense e os Municípios da RMGSL

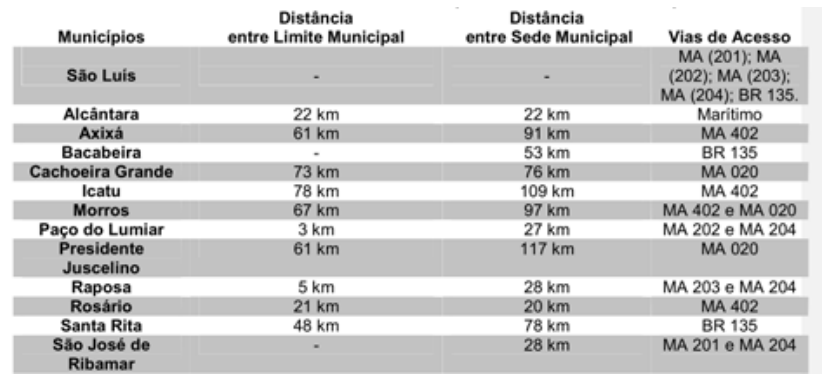

Fonte: SECID/SAAM, a partir de dados de Google Earth, 2015.

\subsection{Produto Interno Bruto - PIB}

Os aspectos econômicos apontam quais são os pontos fortes e fracos do modelo vigente que se reproduz dentro de um espaço dicotômico e segregado espacialmente. O Produto Interno Bruto - PIB de uma RM qualifica os fluxos de capital que circula e é produzido nas cidades, demonstrando uma pujança econômica ou subsistência.

No estado do Maranhão, nota-se a presença de municípios com taxas de crescimento econômico acima da região Nordeste ou até mesmo acima dos níveis esperado para o país, como observado na análise do Produto Interno Bruto - PIB por município. Observa-se elevação constante do PIB da RMGSL no período de 2010 a 2013, com crescimento da ordem de 11\% e 14\% entre os anos de 2011 e 2012 respectivamente (Gráfico 01).

De acordo com o IMESC (2016), a RMGSL representa 39,4\% do PIB do Maranhão contabilizando R \$ 30,2 bilhões de reais. Destes $87 \%$ está concentrado na capital maranhense no ano de 2014. A parcela do PIB da RMGSL restante divide-se entre os municípios de São José de Ribamar, Paço do Lumiar e Bacabeira concentram 9\% do PIB, enquanto 4\% é redistribuído entre Alcântara, Axixá, Cachoeira Grande, Icatu, Morros, Raposa, Rosário, Presidente Juscelino e Santa Rita (Figura 06).

Nitidamente percebe-se que a riqueza gerada na RMGSL está concentrada em São Luís, o que atrai um grande fluxo migratório originado pelos municípios limítrofes que 
atuam principalmente como cidades-dormitórios e segundas residências ou mesmo de municípios mais longínquos que buscam oportunidades de emprego. Esse cenário de centralização econômica na capital amplia as desigualdades sociais e provoca a redução da qualidade de vida na região.

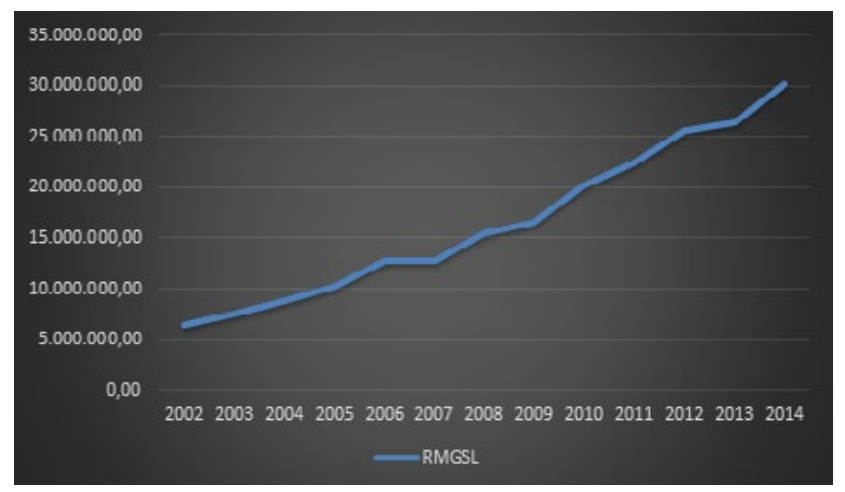

Gráfico 01: Produto Interno Bruto da RMGSL entre os anos de 2002 a 2014..

Fonte: IMESC, 2016

Compondo o PIB têm-se o Valor Adicionado no setor de Serviços onde nota-se uma grande concentração de seu percentual nos municípios de São Luís, São José de Ribamar e Paço do Lumiar, destacando-se as áreas da Administração pública e Comércio, enquanto que municípios como Axixá, Presidente Juscelino e Cachoeira Grande alcançam os menores percentuais. Nesse comparativo evidencia-se a grande disparidade existente na RMGSL, onde a Capital concentra 88\% do Valor Adicionado de Serviços da região (Figura 07).

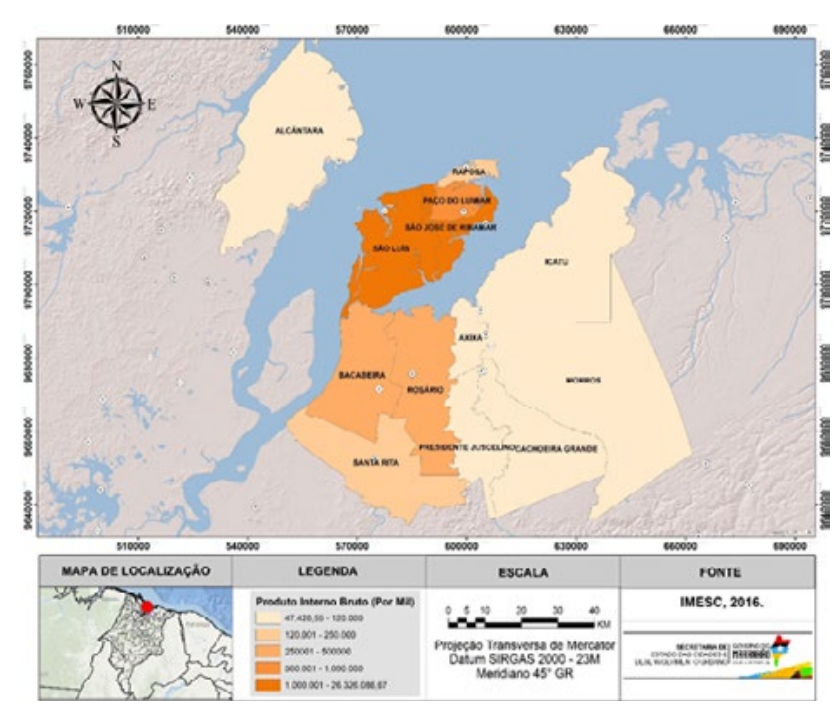

Figura 06: Mapa do PIB da RMGSL em 2014.

Fonte: IMESC, 2016

Em relação ao Valor Adicionado Agropecuário visualiza-se que os maiores percentuais estão localizados no município de Presidente Juscelino seguido por São Luís, Icatu e
Rosário, estes municípios possuem uma crescente demanda agropecuária com o VA superior ao de São Luís e São José de Ribamar, enquanto Morros e Paço do Lumiar contabilizam os menores percentuais (Figura 08).

No setor industrial nota-se uma indústria centrada na extração e transformação, destaca-se a VALE, ALUMAR que alicerçado pelo complexo portuário formado pelos terminais do Itaqui, Ponta da Madeira e ALUMAR agregam suas atividades setorizadas em outras regiões do estado, colocando em evidência os aspectos de logísticas de escoamento da produção no estado e Região Metropolitana.

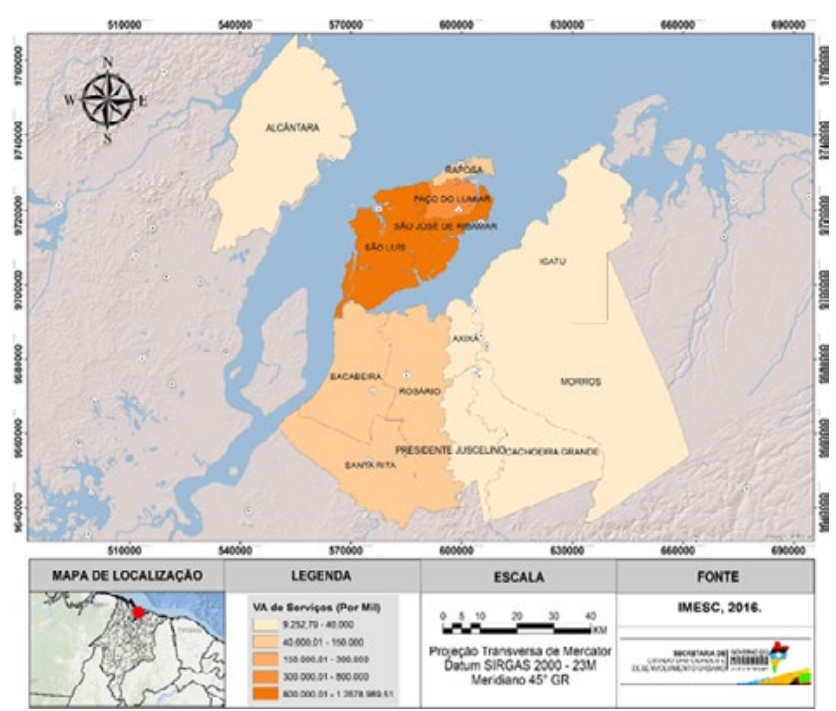

Figura 07: Mapa do VA de Serviços da RMGSL em 2014.

Fonte: IMESC, 2015

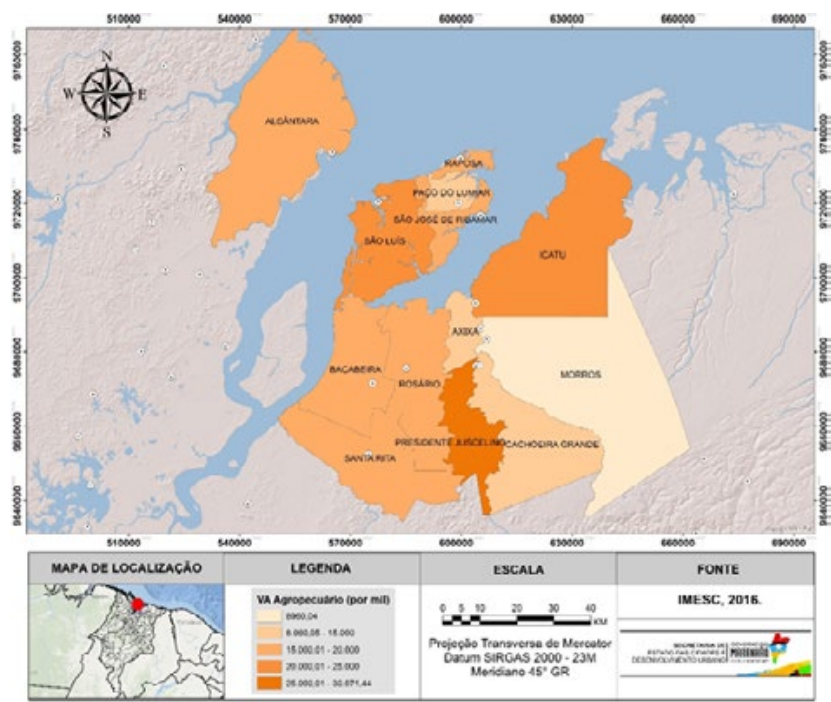

Figura 08: Mapa do VA Agropecuário da RMGSL em 2014. Fonte: IMESC, 2015

A construção civil também possui grande destaque principalmente na Capital Maranhense que concentra 90\% do Valor Adicionado Industrial da RMGSL, seguido por São José de Ribamar, Paço do Lumiar e Bacabeira. O município 
de Rosário também se destaca pelo seu potencial para extração mineral, extraindo, principalmente, substâncias como granito, argila e areia. Na RMGSL, nota-se municípios com características rurais e baixa atividade industrial, como os municípios de Axixá, Presidente Juscelino e Cachoeira Grande. (Figura 09).

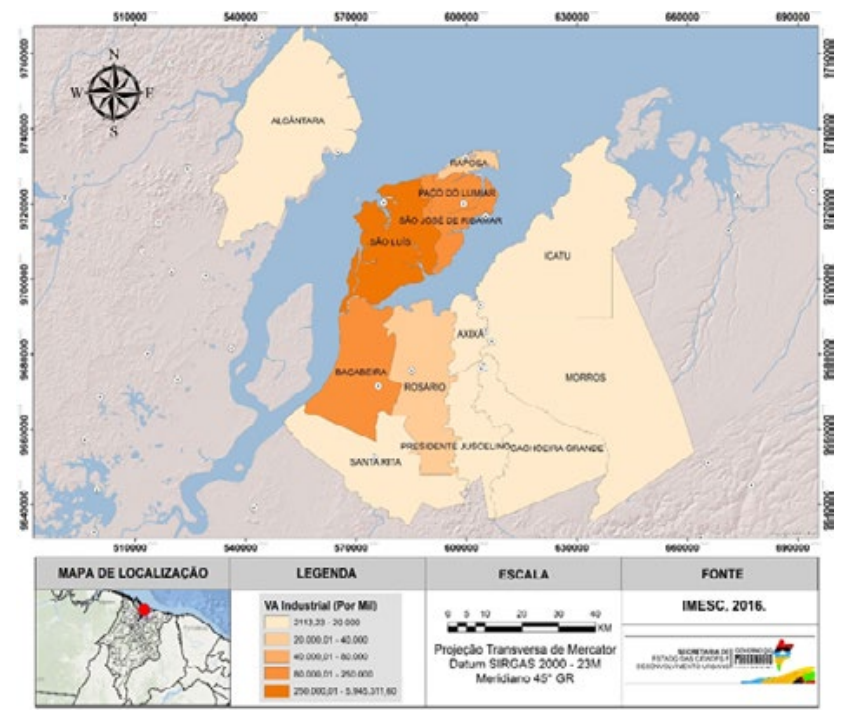

Figura 09: Mapa do VA Industrial da RMGSL em 2014.

Fonte: IMESC, 2016

Esse caráter acumulativo é fruto da organização do território, direcionado pelas centralidades e hierarquização existente, notadamente marcada por questões históricas. Deste modo, o município de São Luís, atendendo a demanda existente concentra os principais serviços urbanos na RMGSL, por conseguinte, acaba exercendo uma força centrípeta de hierarquia urbana, ligando seu tecido urbano aos outros municípios da região. Porém, áreas de interesses comuns aos municípios da RMGSL devem ser alvos de diálogos e/ou gestão compartilhada, com direcionamento ligado a criação de novas centralidades visando à redução da concentração produtiva e desigualdade local e regional existente.

\subsection{IDHM Renda}

A renda per capita dos brasileiros teve um ganho considerável nos últimos anos. A RMGSL segue esse crescimento, como mostra o IDH Renda da região que em 2000 registrava 0, 618; já em 2010 houve um aumento significativo da renda per capita alcançando 0, 693 (Gráfico 02).

Os municípios de Rosário e Bacabeira obtiveram o maior crescimento do IDH Renda da RM. No entanto, ainda há uma grande desigualdade entre os municípios da RMGSL, haja vista a grande concentração de renda concentrada em São Luís, Paço do Lumiar e São José de Ribamar, enquanto os municípios de Presidente Juscelino e Cachoeira Grande permanecem com os piores indicadores de renda com 0,452 e 0,422 respectivamente.

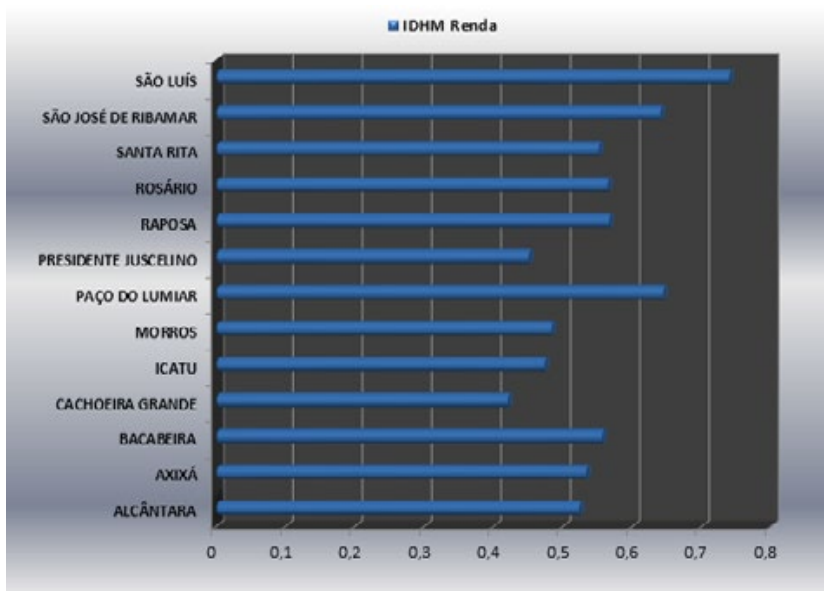

Gráfico 02: IDHM Renda da RMGSL em 2010.

Fonte: IPEA, 2013

\subsection{População na Força de Trabalho}

De acordo com o IBGE (2010), a População na Força de Trabalho - PFT do Maranhão é de 2.585.063 pessoas, $\operatorname{com} 27 \%$ situados nos municípios que compõem a RMGSL. No entanto, quando se avalia os empregos formais via CLT e estatutários percebe-se que apenas 28,58\% da PFT do estado é contemplada, além de ter concentrado 52,57\% dos empregos formais do Maranhão na RMGSL.

A população economicamente ativa na RMGSL alcança 697 mil pessoas, onde 55,68\% atuam sob regime de CLT e estatutário, nota-se que 91\% destes estão localizados em São Luís, seguida por São José de Ribamar e Paço do Lumiar em termos quantitativos. Deve-se frisar que o município de Bacabeira registra um alto percentual de empregos formalizados concentrados no setor industrial, alcançando $46 \%$ de sua população com CLT ou estatutário, enquanto Cachoeira Grande e Icatu percentuais inferiores a 10\% (Tabela 03).

Assim os indicadores apontados nos fazem entender os elementos essenciais da situação local e regional a partir das diferenciações socioespaciais. Para contrapor a essa realidade deve-se compreender a produção do espaço e o desenvolvimento do processo de diferenciação, visando desenvolver e efetivar estratégias territoriais capazes de articular, integrar e reduzir as desigualdades sociais e econômicas existentes. 
Tabela 03: População na Força de Trabalho e Contratos CLT e Estatutá rios.

\begin{tabular}{|cccc|}
\hline MUNICIPIOS & $\begin{array}{c}\text { CONTRATOS CLT E } \\
\text { ESTATUTÁRIOS }\end{array}$ & PFT & $\mathbf{( \% )}$ \\
\hline Alcåntara & 1.626 & 7.692 & $21,13 \%$ \\
\hline Axixá & 465 & 4.255 & $10,92 \%$ \\
\hline Bacabeira & 2.690 & 5.812 & $46,28 \%$ \\
\hline Cachoeira Grande & 162 & 2.382 & $6,80 \%$ \\
\hline Icatu & 600 & 7.352 & $8,16 \%$ \\
\hline Morros & 1.096 & 6.759 & $16,21 \%$ \\
\hline Paço do Lumiar & 5.788 & 47.547 & $12,17 \%$ \\
\hline Presidente & 468 & 3.052 & $15,33 \%$ \\
Juscelino & 1.957 & 10.382 & $18,84 \%$ \\
\hline Raposa & 2.003 & 16.029 & $12,49 \%$ \\
\hline Rosário & 1.384 & 12.384 & $11,17 \%$ \\
\hline Santa Rita & 16.043 & 71.342 & $22,48 \%$ \\
\hline São José de & 354.124 & 502.567 & $70,46 \%$ \\
Ribamar & 388.406 & 697.555 & $55,68 \%$ \\
\hline Săo Luís & & & \\
\hline RMGSL & & & \\
\hline
\end{tabular}

Fonte: SECID/SAAM, a partir de dados de IBGE, 2010; RAIS, 2014.

\section{CONSIDERAÇÕES FINAIS}

Deve-se avaliar de forma específica cada indicador, tendo em vista as relações em diversas escalas que o ambiente urbano abrange atualmente. Contudo, a relação entre os indicadores evidenciou diversas questões que, associadas, apontam características do ambiente onde vivemos.

Considerando-se os percalços na efetivação da RMGSL, onde os interesses locais sempre prevaleceram, e as diretrizes recentemente colocadas pelo Estatuto da Metrópole, o papel do ente federado estadual como elemento de integração e motor dinâmico do processo de metropolização fica evidente e ganha força. Ainda mais com a inclusão dos municípios de Morros, Axixá, Presidente Juscelino e Cachoeira Grande, na RMGSL, o que exigirá investimentos em infraestrutura e serviços capazes de reforçar ou consolidar a frágil interação econômica e social com estes municípios.

Nesse sentido, as políticas urbanas enfrentam também um problema estrutural, visto que a demanda social cresce acima das ofertas de estrutura pública oferecida pelo Estado, gerando uma insustentabilidade urbana, o que agrava a situação da pobreza urbana. De fato, na configuração proposta, assume-se a enorme desigualdade social existente entre o município pólo e o município com o menor IDHM, colocando uma diretriz clara para qualquer processo de planejamento regional. A diminuição da pobreza é o desafio que se coloca para as políticas metropolitanas, uma vez que "a pobreza é estrutural e não residual. Ela aumenta à medida que a cidade cresce." (SANTOS, 2009, p.18).

O que se verifica na RMGSL é que o planejamento urbano não tem um caráter de "perpetualidade", o que se reflete na gestão das cidades, pois os projetos de melhoria da qualidade de vida da população só se prolongam no tempo e espaço se os grupos políticos também o fizerem. O desenvolvimento urbano nesse sentido é condicionado pelo político, mesmo quando a sociedade civil cria mecanismos de pressão, pois a ideologia dos grupos dominantes até o presente momento sempre coloca seus interesses sobre os da massa dominada

Com as novas propostas de configuração e gestão da RMGSL espera-se que de fato o interesse público se torne superior aos interesses individuais, pois seja qual for sua configuração territorial, ainda temos uma região fragmentada e dominada por grupos políticos individualistas que não abrem mão do poder em favor do bem coletivo. Desse modo, torna-se nítida a importância de uma gestão compartilhada entre os municípios, que precisam resolver os problemas de interesse comum que dificultam o seu desenvolvimento econômico e social.

\section{REFERÊNCIAS BIBLIOGRÁFICAS}

BRASIL, Governo Federal. Lei 13.089 de janeiro 2015.

CORRÊA, Roberto Lobato. A Rede Urbana. São Paulo: Editora Ática, 1989.

DINIZ, Joarez Soares. As condições e contradições no espaço urbano de São Luís (MA): traços periféricos. Ciências Humanas em Revista - São Luís, V. 5, n.1, julho 2007.

DINIZ, Juarez Soares. A dinâmica do processo de segregação sócioespacial em São Luís (MA): $O$ caso da Vila Cascavel. (Dissertação de Mestrado). São Luís: MPP/ UFMA, 1999.

FERNANDES JR. Edésio. Gestão Metropolitana. Cad. Esc. Legislativa., v. 7, $\mathrm{n}^{\circ}$ 12, p. 65-99. Belo Horizonte 2004.

GOMES, Reginaldo Rabelo; SOUSA, Antonia Sueli Silva; DINIZ, Juarez Soares. Pobreza urbana e segregação sócio-espacial em São José de Ribamar - MA: um olhar sobre a comunidade da Campina. São Luís: Anais do VI Internacional de Políticas Públicas - UFMA, 2013.

LIPIETZ, Alan. O capital e seu espaço. São Paulo. Nobel, 1979.

IBGE, INSTITUTO BRASILEIRO DE GEOGRAFIA E ESTATÍSTICAS. Regiões de Influência das Regiões 
2007. Ministério do Planejamento, Orçamento e Gestão. Rio de Janeiro, 2008.

INSTITUTO BRASILEIRO DE GEOGRAFIA E ESTATÍSTICAS. Censo Demográfico 2010 - Microdados. Disponível em < http://www.ibge.gov.br/home/ $>$. Acesso em: 2 set. 2013.

IMESC, Instituto Maranhense de Estudos Socioeconômicos e Cartográficos. Diagnóstico Pré-Liminar do Plano de Ação MAIS IDH. Secretaria de Estado do Planejamento e Orçamento. São Luís, 2015.

IPEA. Infraestrutura social e urbana no Brasil: subsídios para uma agenda de pesquisa e formulação de políticas públicas. Brasilia: Ipea, 2010.

Atlas do Desenvolvimento Humano das Regiões Metropolitanas. Brasília: Ipea, 2013.

MOREIRA, Tiago Silva. Gestão Metropolitana: a região metropolitana da grande São Luís e os desafios das políticas urbanas. (Dissertação de Mestrado) São Luís: UEMA, 2013.

OBSERVATÓRIO DAS METRÓPOLES. Unidades Territoriais Urbanas no Brasil Regiões Metropolitanas, Regiões Integradas de Desenvolvimento Econômico e Aglomerações Urbanas em 2015. São Paulo. 2015.

ROLNIK, Raquel; SOMEKH, Nadia. Governar as Metrópoles: dilemas da recentralização. São Paulo Perspec. vol.14 no.4, p.83-90.

OLIVEIRA, Evagelina. Redes e Regionalização da Saúde. In: BARCELLOS, Christovam. A geografia e o contexto dos problemas de saúde. Rio de Janeiro. ABRASCO. p. $223-230,2008$.

POPPER, Karl R. A lógica da pesquisa científica. São Paulo: Cultrix, 1972.

SANTOS, Milton. Pobreza urbana. São Paulo: Edusp, 2009.

SERPA, Angelo. Lugar e Centralidade em um contexto metropolitano. In: Carlos, Ana Fani Alessandrini. SOUZA, Marcelo Lopes de. SPOSITO, Encarnação Beltrão (Orgs). A Produção do espaço urbano: agentes e processos, escalas e desafios. São Paulo: Contexto, 2012.

SOUZA, Barbara Cecília Machado Fontes de. Desenvolvimento regional e gestão metropolitana: reflexões a partir da política habitacional na região metropolitana de Aracajú. (Mestrado Desenvolvimento Regional e Gestão de Empreendimentos Locais). São Cristóvão, Universidade Federal de Sergipe, Sergipe: 2009.

SOUZA, Marcelo Lopes de. Mudar a cidade: uma introdução crítica ao planejamento e à gestão urbana. Rio de Janeiro: Bertrand Brasil, 2010

Correspondência dos autores:

Yata Anderson Gonzaga Masullo e-mail: yanderson3@hotmail.com

José Antonio Viana Lopes

e-mail: joseantonioarq@gmail.com

Artigo recebido em: 25/01/2016

Revisado pelo autor em: 16/11/2016

Aceito para publicação em: 10/01/2017 